\title{
Narrativas dos movimentos de uma tese: apresentar as entrevistadas e narrar o narrado
}

\author{
MARIA CECÍLIA TORRES
}

\begin{abstract}
Maria Cecília de Araújo Rodrigues Torres possui mestrado em Educação pela Pontifícia Universidade Católica do Rio Grande do Sul (1995), doutorado em Educação pela Universidade Federal do Rio Grande do Sul (2003) e doutorado Sandwiche- na University of Queensland/School of Education/Au (2003), sob a orientação do Prof. Allan Luke. Desde 1997 é pesquisadora do grupo Cotidiano e Educação Musical da Universidade Federal do Rio Grande do Sul, PPGMúsica-UFRGS (CNPq), sob a coordenação da profa. Dra. Jusamara Souza. Atuou como educadora musical na escola de educação básica por mais de 20 anos na educação infantil e ensino fundamental. Foi coordenadora do Curso de música - Licenciatura do Centro Universitário Metodista IPA (desde janeiro de 2011 a janeiro de 2014) e atua como professora do curso de música do Centro Universitário Metodista IPA desde 2008. Tem experiência na área de Artes, com ênfase em Educação musical, atuando principalmente nos seguintes temas: educação musical, atividades musicais, formação de professores, arteterapia na educação e identidades musicais com narrativas de si e pesquisa autobiográfica. Foi Editora da Revista da ABEM (Associação Brasileira de Educação Musical) nas gestões 2005-2007 e 2009-2011.e presidente do Conselho editorial da ABEM nas gestões 2007-2009 e 2011-2013. É coordenadora do Subprojeto Música do Projeto PIBID-IPA-CAPES desde agosto de 2012.
\end{abstract}




\section{- RESUMO}

O presente artigo é uma síntese revisitada de um capítulo de uma tese de doutorado o qual apresenta as entrevistadas da pesquisa na perspectiva de uma abordagem com narrativas de si e (auto)biografias. O grupo é composto por vinte mulheres, todas estudantes de um Curso de Graduação em Pedagogia e com a grande maioria que já atua como professora da educação infantil ou das séries iniciais do ensino fundamental. Como um trabalho que dialoga a partir do campo dos Estudos Culturais em Educação e da Pesquisa Biográfica, destaco autores como Arfuch (2010), Délory-Momberger (2012), Souza (2014), Abrahão (2014), dentre outros, para compor o embasamento teórico. As entrevistadas são apresentadas através de suas narrativas das memórias musicais de diferentes fases da vida, com lembranças de sons, melodias, discos e cantores. No momento da análise dos dados que emergiram com as entrevistas e as autobiografias musicais foram organizados mapas com dados de cada entrevistada, no sentido de poder conhecer as trilhas sonoras de cada etapa de suas vidas e as articulações destas com as práticas pedagógico musicais.

\section{- PALAVRAS-CAVE}

Narrativas de si, memórias musicais, pesquisa (auto)biográfica.

\section{ABSTRACT}

This is a revisited synthesis of a chapter of a $\mathrm{PhD}$ thesis which introduces the research interviews in the perspective of an approach with self narratives and autobiogaphies. The group $i$, being the vast majority already working as college teachers or teachers in the initial series of elementar school. As a study that inserts itself in the field of Cultural studies in education and Biographic research, authors as Josso (2004), Arfuch (2010), Délory-Momberger (2006), Souza (2014), Maffioletti, and Abrahão (2016) are pointed among others as the theoretical basis. The interviewed subjects are presented through its narratives of musical memories in the diferente phases of their lives, with remembrances of sounds, melodiees, recorded material, and singers. In the moment of data analysis based upon the interviews and musical autobiographies, those were as maps of each interviewed teacher, in order to the author to get the knowledge and the meaning of the sound tracks of each step of their lives and the interaction of them with their praactice of musical pedagogy.

\section{KEYWORDS}

Self narratives; musical memories; autobiographical research.

\section{Adentrando no campo (auto)biográfico}

Olhar para o passado pode ajudar-nos a encontrar explicação para significados nas ações que temos hoje como pessoas que foram construindo um percurso pessoal e profissional rico de cruzamentos com os outros e a dar sentido ao nosso posicionamento como professoras e formadoras de professores (FREITAS e GALVÃO, 2007, p.218). 
Ao iniciar o prefácio dessa escrita narrativa (auto) biográfica, com as lembranças e fragmentos de cenas vividas como professora/pesquisadora que aprende e ressignifica constantemente neste espaço, com seus rituais e vacilações, inspiro-me nas palavras de Freitas e Galvão (2007) como um mote para as reflexões que trago e o exercício de narrar movimentos de uma tese, tendo tido a ajuda e a generosidade de muitos interlocutores para a realização da citada pesquisa.

Apresento dessa maneira esse trabalho como uma síntese revisitada da narrativa de um capítulo da minha tese de doutorado realizada em um Programa de Educação/Linha dos Estudos Culturais em Educação, no campo dos estudos biográficos e (auto) biográficos, com foco nas identidades musicais de um grupo de professoras do ensino fundamental e também alunas de um curso de Graduação em Pedagogia, no sentido de apresentar as vinte entrevistadas com excertos de suas narrativas orais e escritas.

Essa tese de doutorado foi concluída e defendida em 2003 e após mais de uma década de ter coletado e analisado esses dados, assumo novamente o papel de narradora na perspectiva de compartilhar alguns processos que envolveram a escolha das entrevistadas, todas mulheres, para um trabalho com narrativas de si, entrelaçando áreas do conhecimento como a Educação, os Estudos Culturais e a Educação Musical e, dessa maneira, recontar essas histórias.

Ao longo desses anos, entre o término do trabalho e hoje (2017), ano em que reescrevo e reconto algumas narrativas de excertos, pesquisei no sentido de conhecer autores que desenvolviam pesquisas nessa perspectiva, assim como periódicos, livros, Seminários e Congressos que apresentassem discussões e trabaIhos no campo biográfico. A participação em vários CIPAS (Congresso Internacional de Pesquisa (Auto)biográfica), já na sua primeira edição realizada na PUC/RS, em Porto Alegre (2004) e com a oportunidade de conhecer os trabalhos de professores e pesquisadores como Abrahão (2003, 2013, 2014), Souza (2003, 2014, 2016), Passeggi $(2003,2006,2014)$, dentre outros no Brasil e autores da literatura internacional que eu não havia conhecido ao longo da minha pesquisa de tese como Delory-Momberger (2006, 2008, 2012), Pineau (2006), Josso (2004), Bolívar (2005) e Formenti (2013, 2016).

Ainda nesse campo cito também alguns autores com pesquisas de mestrado e doutorado no Brasil, sem a pretensão de incluir todos, nas áreas dos estudos Biográficos e (Auto)biográficos com o foco em temáticas da Educação Musical e Educação, os quais tive a oportunidade de conhecer seus trabalhos. Dentre as pesquisas de doutorado e pós-doutorado realizadas nesse espaço de tempo cito os autores e as áreas dos Programas de Pós-Graduação onde foram realizadas como o de Garbosa (2003- Música), Louro (2005- Música), Freitas (2006- Educação), Abreu (2011- Música) e Maffioletti (2014- Educação). Já no contexto dos mestrados destaco os trabalhos de Silva (2012 - Artes/Música), Lutz (2013 - Letras), Lima (2013 - Educação), Gaulke (2013- Música), Pedrini (2013 - Educação), Anders (2014- Educação), Fugimoto (2015 - Música) e Almeida (2016- Educação), dentre outros realizados ou em andamento.

Ressalto que foram muitas as descobertas deste/neste amplo espaço biográfico, com seus desafios de pesquisa e o fato de que era no ano de 2003 uma abordagem em pesquisa ainda pouco trabalhada nas áreas dos Estudos Culturais em Educação e na Educação Musical no Brasil, com muitas possibilidades de 
escutas e narrativas para serem conhecidas e socializadas e a busca por diálogo com outras áreas do conhecimento que trabalhavam nessa perspectiva teórico-metodológica. Assim, essas narrativas estão em um movimento constante de ir e vir e de narrar e ser narrado.

\section{As entrevistadas: quem são elas?}

Ao apresentar o grupo de vinte entrevistadas que deram corpo e vida à tese, com suas narrativas orais e escritas, escolho as palavras de Formenti (2013) como embasamento no momento em que revisito as narrativas escritas na tese e narro em um outro espaço e tempo, buscando contextualizar o narrado e datado para os limites desse artigo. Nesse sentido a citada autora pontua que:

[...] escolho, portanto, a narrativa como a porta de entrada - métodos "biograficamente orientados" - porque acho que narrar seja o modo de representar a experiência (dentre muitos) mais próximo e mais respeitoso com a ação que a criou. É na narrativa que se reconstrói a ação, a interação com o mundo, graças à qual a experiência humana pode ter lugar. É na narrativa que se celebra as relações e a dinâmica de cada saber nosso e da nossa identidade (FORMENTI, 2013, p.115).

A partir da citação de Formenti, apresento esse grupo de mulheres, todas alunas de um mesmo curso de Graduação em Pedagogia, numa Universidade em Porto Alegre/RS e nascidas no Rio Grande do Sul, entre os anos de 1947 e 1982. A grande maioria do grupo estava cursando o terceiro semestre do Curso de Licenciatura em Pedagogia, sendo que quatro alunas estavam no quinto e uma no sétimo semestre. Um fato a ressaltar é que desse grupo de vinte doze delas já estavam atuando como professoras do ensino fundamental, em escolas da rede pública e particular, nas séries iniciais, e quatro delas haviam realizado estágios ou estavam realizando atividades voluntárias em ambientes escolares.

Como o grupo foi constituído? Visitei as salas de aulas no momento de duas aulas da disciplina de Educação Artística/Educação Musical e fiz uma breve explanação na que detalhei o projeto de doutorado para as turmas e solicitei a colaboração dos alunos, uma vez que a professora havia cedido esse espaço de maneira muito especial para que eu apresentasse a pesquisa, explicasse as opções metodológicas e fizesse o convite para aquelas alunas que quisessem e pudessem participar do trabalho. Destaco ainda que a acolhida da professora da turma, comentando previamente com o grupo sobre a minha pesquisa, foi um fator determinante para estabelecer a atenção no primeiro contato com as entrevistadas e o desejo de muitas delas participarem.

Comentei que iriamos trabalhar com as narrativas de si de cada uma delas e que teria um momento de entrevistas com as o trabalho com narrativas orais que seriam gravadas e depois transcritas e que elas também escreveriam suas (auto)biografias musicais, constituindo-se como as narrativas escritas, Seria um contar-se entre o oral e o escrito, trazendo fatos do vivido e contando suas histórias. Assim sendo, destaquei essa passagem de uma obra de Delory-Momberger, (2006) 
na qual a autora nos conta que

\begin{abstract}
A narrativa transforma os acontecimentos, as ações e as pessoas do vivido em episódios, em enredos e em personagens; ordena os acontecimentos no tempo e constrói entre eles relações de causas, de consequências, de fim, dando, assim, um lugar e um sentido ao ocasional, ao fortuito, ao heterogêneo. Pela narrativa, os homens tornamse os próprios personagens de suas vidas e dão a elas uma história [...] o narrativo é o lugar onde a existência humana toma forma, onde ela se elabora e se experimenta sob a forma de uma história (DELORY'MOMBERGER, 2006, p.39-40).
\end{abstract}

Após o encontro com as duas turmas, organizei uma lista em que as alunas interessadas em participarem da pesquisa colocaram seus dados pessoais como nomes, telefones, e-mails e as possibilidades de horários para a realização das entrevistas. O local combinado para a realização das mesmas foi o próprio prédio da Faculdade de Educação da Universidade, na sala ocupada pelo Núcleo de Pesquisa, o qual a Linha de Pesquisa dos Estudos Culturais em Educação estava vinculada e na qual essa pesquisa de tese estava ancorada. Outo aspecto foi pelo fato de oferecer maior disponibilidade de horários para a realização das entrevistas e mobilidade para as entrevistadas.

Cabe detalhar que as entrevistas envolveram um pequeno ritual, que era iniciado com a apresentação, de minha parte, no momento em que entregava o termo de consentimento, que cada aluna preenchia, assinava, esclarecia alguma dúvida e ficava com uma cópia. Apresentava também uma síntese dos objetivos às alunas, da mesma maneira que o termo de consentimento, com os dados de identificação das entrevistadas e da pesquisadora. Como entrevistadora, organizava e checava o material, gravador e fita, antes das alunas chegarem, e a duração das entrevistas variava muito, mas tendo como uma média trinta minutos de duração. As entrevistas foram realizadas no período compreendido entre os meses de julho e dezembro de 2002, com apenas uma entrevista realizada no início de 2003. Apesar do roteiro básico com as perguntas na proposta de uma entrevista semiestruturada, também constando em um anexo no trabalho final, procurei não manter rigidez na sua sequência e abrir espaço para comentários e questionamentos por parte da entrevistadora e das entrevistadas no sentido de conhecer as narrativas de cada uma das participantes.

No campo das pesquisas (auto)biográficas e narrativas com o uso de entrevistas, Souza (2014) enfatiza que

As disposições construídas num processo de entrevista abrem muitas possibilidades de sentido, formação, compreensão e marcas biográficas da vida entre entrevistador e entrevistado, frente a partilha de experiências de vida e de percursos biográficos vinculados a projetos de pesquisa ou às práticas de formação $(2014$, p.42). 
Em consonância com as palavras de Souza (2014) ressalto também questões intergeracionais das entrevistadas visto que no grupo das vinte participantes da pesquisa encontrei uma aluna que nasceu na década de 40 (em 1947), duas na década de 50 (em 1950 e 1952) e uma na década de 60 (em 1963), sendo que a grande maioria - 15 alunas - nasceu entre os anos de 1976 e 1982. Como entrevistadora, ao conhecer as entrevistadas, as identifiquei como grupo composto de alunas de uma Universidade Federal, com bastante receptividade e acolhida à apresentação da pesquisa e ao convite para participar. Muitas delas tinham vivências em questões de pesquisa por já terem participado já que algumas eram bolsistas de iniciação científica e estavam envolvidas em projetos de pesquisas com professores/as da Instituição, já bastante familiarizadas com a situação de entrevista. Esses aspectos, certamente, foram muito positivos para o encaminhamento e a realização da pesquisa pelo fato da escolha por entrevistas e, de acordo com Sousa e Cabral (2015),

Dado o valor formativo que a entrevista carrega, é importante observar que tal técnica pode significar importante contribuição para a pesquisa. A relevância da entrevista como técnica utilizada nas pesquisas qualitativas é amplamente reconhecida, especialmente nas pesquisas educacionais (SOUSA e CABRAL, 2015, 153).

Considero relevante explicitar como me caracterizei como entrevistadora no contexto dessa pesquisa, destacando que me apresentei para o grupo como uma professora de música que havia trabalhado por mais de vinte anos em escolas de ensino fundamental e que nos últimos cinco anos vinha atuando como educadora musical em cursos de Pedagogia. Falei também que estava ali como uma pesquisadora e aluna de um curso de doutorado para realizar as entrevistas e coletar as autobiografias para meu projeto de tese. Não sendo a professora delas, era, portanto, desconhecida da grande maioria das alunas. É evidente que, ao se engajarem como entrevistadas na conversa, elas tinham uma imagem prévia da entrevistadora e uma expectativa em relação ao que lhe seria perguntado. Tais expectativas e imagens foram, possivelmente, modificadas no decorrer das entrevistas.

Nesse momento das entrevistas também solicitava que as alunas escrevessem as autobiografias musicais, pedindo que organizassem as narrativas do que lembravam, sem precisar obedecer a um formato único ou número de páginas e regras a seguir. A elaboração desse material poderia ser manuscrita ou em formato digital e elas me enviariam por email ou entregariam pessoalmente. Esse material foi nomeado de (auto)biografias musicais e as entrevistadas colocam um título nos seus escritos, personalizando suas narrativas. Nesse sentido, Souza (2007) argumenta que

Tomar a escrita de si como um caminho para o conhecimento, numa perspectiva hermenêutica, não se reduz a uma tarefa técnica ou mecânica. O pensar em si, falar de si e escrever sobre si emergem em um contexto intelectual de valorização da subjetividade e das experiências privadas. Neste sentido, o conceito de "si mesmo" é, como todo conceito, uma proposta organizadora de determinado princípio de racionalidade (SOUZA, 2007, p. 68). 


\section{A escolha dos nomes: Yasmin, Capitu ou Fernanda?}

Tão logo as entrevistas foram sendo realizadas, percebi que precisava voltar à sala de aula e pedir que as alunas escolhessem um nome pelo qual gostariam de ser identificadas na pesquisa, pois teriam sua identidade real preservada ao longo do trabalho, nos excertos de falas e trechos das autobiografias. Foi um momento importante como pesquisadora, pois pude conhecer os diferentes motivos que levaram as alunas a escolherem esses outros nomes, como o fato de "gostarem" do mesmo, de fazerem associações entre aquele nome e personagens de livros, filmes e peças teatrais, artistas de cinema, cantoras ou pessoas amigas, além do fato de que algumas relataram que as vezes confundiam seus nomes e eram chamadas por algumas pessoas por esses nomes.

Em relação aos nomes escolhidos pelas entrevistadas para a tese, trago o comentário de Pais (2003), em sua obra sobre a vida cotidiana, na qual o autor pontua que:

O nome é uma denominação distintiva pela qual se conhece uma pessoa [...]. De que maneira as pessoas reagem à tentativa de fixarem a sua identidade por antecipação através de um nome? Que sentimentos de indiferença, rejeição ou aceitação desenvolvem ao nome que têm? (PAIS, 2003, p.12).

Pais prossegue em duas reflexões e destaca algumas abordagens relacionadas à questão identitária e aos nomes das pessoas, possibilitando, desta maneira, fazer uma aproximação com o momento da pesquisa de autonomeação das alunas. Um outro enfoque relacionado à identificação de falantes nas transcrições e no próprio texto final de uma investigação, neste caso em pesquisas com estudos de linguagem, vem do trabalho de Garcez (2002), em que o autor descreve que essas atividades "que à primeira vista podem parecer resultados de práticas simples e objetivas, envolvem muitas vezes a atribuição de identidade aos participantes da interação".

Compartilho com as ideias de Garcez e articulo-as com o cenário das entrevistas, tanto no decorrer das transcrições das falas das entrevistadas quanto no momento em que pedi que se autonomeassem para o trabalho. Destaco que algumas entrevistadas, talvez três, ficaram em dúvida quanto ao nome que escolheriam e não se decidiram naquele momento, enviando posteriormente por e-mail suas escolhas de nomes.

Fica, assim, o grupo já autonomeado, composto por Aline, Ana, Beatriz, Capitu, Carolina, Eva, Fernanda, Gisele, Isabela, Joana, Liliane, Madalena, Manoela, Márcia, Margarete, Milena, Roberta, Sofia, Viviane e Yasmin.

\section{Organizando os mapas: lendo, relendo e delineando as identidades}

Abro esse tópico com as narrativas de Chassot (2012) pois assim como o autor, acredito que ao longo desse artigo 
[...] não tenha feito uma narração tradicional, procurei ruínas de narrativas, fiz uma transmissão entre cacos de uma tradição em migalhas, portanto uma renovação das memórias. Talvez tenha guardado na figura do narrador um aspecto mais humilde, muito menos triunfante (CHASSOT, 2012, p.17).

Apresento a seguir as vinte entrevistadas, através de fragmentos de seus 'mapas' que construí para visualizar e organizar as narrativas e excertos das autobiografias e entrevistas, para então ter condições de pinçar trechos que considerei significativos e, então, proceder à análise dos materiais num constante exercício de dialogar com os autores. Sei que tais 'mapas' também são resultado de uma operação discursiva minha, que consistiu em ler e reler as entrevistas e autobiografias de cada uma várias vezes, detendo-me em alguns trechos e tentando ver as falas mais significativas - ou aquelas que pudessem sintetizar/ressaltar determinados aspectos - a partir de cada questão do roteiro das entrevistas. Em muitos casos, marcava determinados trechos da entrevista para preencher os mapas, voltava ao roteiro e, muitas vezes, logo encontrava algum outro excerto que considerava mais apropriado para dar visibilidade aos fragmentos das memórias e identidades musicais do grupo. Foi um processo de construção e reconstrução constante, assumindo o papel de narradora das narrativas.

O próximo passo foi a organização dos dados com uma diagramação que possibilitasse a apresentação de cada participante, com suas características de identificação, suas especificidades quanto a escolhas musicais em diferentes épocas e espaços e, ao mesmo tempo, permitindo que as recorrências e diferenças nas falas quanto a determinados temas, pudessem ser percebidas, lidas, agrupadas e separadas. Confesso que até chegar a esta diagramação ou 'desenho dos mapas', que considerei a mais viável para proceder à análise das narrativas escritas e orais, experimentei e mudei as figuras de lugar inúmeras vezes, ora aumentando para inserir um texto maior, ora diminuindo para retirar ou substituir um excerto.

Considero que esta construção dos 'mapas' foi para mim, pesquisadora e também narradora nessa perspectiva de contar, um exercício de garimpar falas e que essa versão certamente corresponde a este meu momento de escrita e reflexão, com meu olhar captando alguns fatos e discursos e deixando de lado outros. Provavelmente em outro momento de reescrita, esses mapas já sofreriam modificações, talvez com acréscimos de falas e até mudança na diagramação e, foi o que realizei para essa reescrita, fazendo uma síntese e deixando que as narrativas das entrevistadas as apresentassem.

\begin{tabular}{|l|l|l|}
\hline Nome & Idade & \multicolumn{1}{c|}{ Memórias musicais } \\
\hline Aline & 21 & $\begin{array}{l}\text { "Quando eu fiz a 1a. comunhão...eu tinha uns dez } \\
\text { anos... a gente tinha aula e depois tínhamos de ir para } \\
\text { a igreja cantar...eu sabia cantar quase todas as } \\
\text { músicas, e adorava cantar...eu até peguei o livrinho } \\
\text { da igreja, não sabia o ritmo, não sabia nada. Eu } \\
\text { inventava o ritmo e cantava em casa". }\end{array}$ \\
\hline
\end{tabular}




\begin{tabular}{|l|l|l|}
\hline Nome & Idade & \multicolumn{1}{c|}{ Memórias musicais } \\
\hline Ana & 22 & $\begin{array}{l}\text { "Fiz 1a. Comunhão, frequentei grupo de jovens e eu } \\
\text { sempre adorava ir à missa, mais pra cantar. Quando } \\
\text { Eu soube que cantar é rezar duas vezes, eu fiquei } \\
\text { faceiríssima, não é?" }\end{array}$ \\
\hline
\end{tabular}

\begin{tabular}{|l|l|l|}
\hline Nome & Idade & \multicolumn{1}{c|}{ Memórias musicais } \\
\hline Beatriz & 22 & $\begin{array}{l}\text { "A música para mim serve como forma de relaxar e } \\
\text { expor meus anseios, meus sentimentos. Quando "A } \\
\text { música para mim serve como forma de relaxar e } \\
\text { expor meus anseios, meus sentimentos. Quando } \\
\text { estou triste ouço Rock, pois expresso minha } \\
\text { indignação através de uma música em volume alto e } \\
\text { é de certa forma agressiva, pois se escutar uma } \\
\text { música instrumental posso começar a chorar...". }\end{array}$ \\
\hline
\end{tabular}

\begin{tabular}{|l|l|l|}
\hline Nome & Idade & \multicolumn{1}{c|}{ Memórias musicais } \\
\hline Capitu & 23 & $\begin{array}{l}\text { "não sei se era porque eu era do interior ou não, } \\
\text { assim, eu fui muito influenciada pelos adultos [...] } \\
\text { Então a música Sertaneja me marcou bastante, eu } \\
\text { era fã do Leandro e Leonardo! Eu cheguei a } \\
\text { emagrecer 15 quilos porque eu coloquei na minha } \\
\text { cabeça que ia conhecer o Leandro". }\end{array}$ \\
\hline
\end{tabular}

\begin{tabular}{|l|l|l|}
\hline Nome & Idade & \multicolumn{1}{c|}{ Memórias musicais } \\
\hline Carolina & 40 & $\begin{array}{l}\text { "Tenho certeza que cada momento da minha vida } \\
\text { tem uma trilha sonora. Se pudesse escutar todas as } \\
\text { músicas das quais me lembro, certamente momentos } \\
\text { vividos ficariam ainda mais vivos em minha mente. É } \\
\text { impressionante como a música, ativa a memória de } \\
\text { tal forma em minha mente, que ao fazer tal relato, foi- } \\
\text { me possível reviver cada momento destes que falei. } \\
\text { Parece que se volta ao passado, revendo até os } \\
\text { episódios". }\end{array}$ \\
\hline
\end{tabular}

\begin{tabular}{|l|l|l|}
\hline Nome & Idade & \multicolumn{1}{c|}{ Memórias musicais } \\
\hline Eva & \multirow{2}{*}{22} & $\begin{array}{l}\text { "Quando eu fiz o meu estágio, eu trabalhei bastante } \\
\text { com música. Eu sempre na recreação usava música, } \\
\text { quando eles pediam. Eles levavam os CDs próprios } \\
\text { pra me mostrar e era sempre utilizado nas aulas [...] } \\
\text { Eu quis fazer o contrário do que sempre foi feito por } \\
\text { mim". }\end{array}$ \\
\hline
\end{tabular}

\begin{tabular}{|l|l|l|}
\hline Nome & Idade & \multicolumn{1}{c|}{ Memórias musicais } \\
\hline Fernanda & 27 & $\begin{array}{l}\text { "Hoje em dia sinto falta de ouvir música. Passo o dia } \\
\text { fora entre a faculdade e o trabalho e em nenhum dos } \\
\text { dois lugares posso escutar. À noite chego cansada e } \\
\text { também não consigo ouvir nada. Bem, (eu) tenho } \\
\text { uma mania: tudo eu relaciono à música: fatos, } \\
\text { pessoas". }\end{array}$ \\
\hline
\end{tabular}




\begin{tabular}{|l|l|l|}
\hline Nome & Idade & \multicolumn{1}{c|}{ Memórias musicais } \\
\hline Gisele & 26 & $\begin{array}{l}\text { "Gostava do balão Mágico, do Jairzinho e da Simony. } \\
\text { Eu e minha irmã tínhamos o LP deles que na capa } \\
\text { apareciam os dois - ele de terninho e ela de vestido } \\
\text { rodado branco - com um fundo azul estrelado e os } \\
\text { dois sentados na lua". }\end{array}$ \\
\hline
\end{tabular}

\begin{tabular}{|l|l|l|}
\hline Nome & Idade & \multicolumn{1}{c|}{ Memórias musicais } \\
\hline Isabela & 25 & $\begin{array}{l}\text { "Mas acho que a minha vida inteira foi aquela coisa } \\
\text { de; momentos tristes ouvir uma música, momentos } \\
\text { felizes ouvir outra música. Sempre tinha uma música } \\
\text { que lembrava alguma situação...". }\end{array}$ \\
\hline
\end{tabular}

\begin{tabular}{|l|l|l|}
\hline Nome & Idade & \multicolumn{1}{c|}{ Memórias musicais } \\
\hline Joana & 24 & $\begin{array}{l}\text { "Walkman também, até hoje eu ainda escuto } \\
\text { walkman, principalmente assim se vou ter um dia } \\
\text { muito cheio, assim muito longo, eu boto o walkman } \\
\text { que é uma maneira de me deixar mais ligada, não me } \\
\text { cansar tanto". }\end{array}$ \\
\hline
\end{tabular}

\begin{tabular}{|l|l|l|}
\hline Nome & Idade & \multicolumn{1}{c|}{ Memórias musicais } \\
\hline 21 & $\begin{array}{l}\text { "No entanto quando trabalhei em creche, } \\
\text { interessante foi o trabalho para resgatar brincadeiras } \\
\text { Liliane }\end{array}$ & $\begin{array}{l}\text { antigas: "brincadeiras de nosso pais". Como não } \\
\text { poderia deixar de ser, as brincadeiras de roda vieram } \\
\text { com muita força e com elas as tradicionais cantigas } \\
\text { que algumas crianças não conheciam". }\end{array}$ \\
\hline
\end{tabular}

\begin{tabular}{|l|l|l|}
\hline Nome & Idade & \multicolumn{1}{c|}{ Memórias musicais } \\
\hline Madalena & 56 & $\begin{array}{l}\text { "Quando eu comecei a fazer o normal, eu já não tive } \\
\text { assim... não uma lembrança muito boa, porque uma } \\
\text { irmã que fazia... nós tínhamos música, mas ela, fez } \\
\text { um teste e achou que eu não tinha capacidade pra } \\
\text { cantar. Eu desafinava, então a música ficou pra mim, } \\
\text { assim, tanto esquecida, pra falar a verdade...eu ficava } \\
\text { mais fechada no meu canto". }\end{array}$ \\
\hline
\end{tabular}

\begin{tabular}{|l|l|l|}
\hline Nome & Idade & \multicolumn{1}{c|}{ Memórias musicais } \\
\hline Manoela & 21 & $\begin{array}{l}\text { "Na sala de aula, a professora escolhia sempre um } \\
\text { disco de alguma história para trabalhar num bimestre } \\
\text { ou semestre. Era positivo porque tínhamos sempre } \\
\text { uma orientação, mas em compensação, enjoávamos } \\
\text { muito rápido por ser somente o que se falava na sala } \\
\text { de aula". }\end{array}$ \\
\hline
\end{tabular}




\begin{tabular}{|l|l|l|}
\hline Nome & Idade & \multicolumn{1}{c|}{ Memórias musicais } \\
\hline Márcia & 53 & $\begin{array}{l}\text { "Após os 30 anos conheci a "Biodanca", foi então que } \\
\text { ampliei meu gosto pela música. Comecei até a gostar } \\
\text { de samba e pagode. Nesta época comprava CDs de } \\
\text { música popular brasileira; a música começa a fazer } \\
\text { parte da minha vida, ouvia em casa, no carro e em } \\
\text { shows" }\end{array}$ \\
\hline
\end{tabular}

\begin{tabular}{|l|l|l|}
\hline Nome & Idade & \multicolumn{1}{c|}{ Memórias musicais } \\
\hline Margarete & 51 & $\begin{array}{l}\text { "O tempo passou de repente e quem estava } \\
\text { cantando canções de ninar, era eu, para minhas } \\
\text { filhas. Nesta época eu era professora de educação } \\
\text { infantil e ensinava a elas todas as canções que } \\
\text { cantava com meus alunos: A casa..." }\end{array}$ \\
\hline
\end{tabular}

\begin{tabular}{|l|l|l|}
\hline Nome & Idade & \multicolumn{1}{c|}{ Memórias musicais } \\
\hline Milena & 21 & $\begin{array}{l}\text { "Também me lembro da professora que na 1a. série } \\
{[\ldots] \text { até hoje, eu tenho lembranças bonitas dessa }} \\
\text { professora, gosto de me identificar com ela porque } \\
\text { ela transmitia muito mais do que o currículo, né? } \\
\text { Transmitia valores, explorava assim, a criatividade do } \\
\text { aluno". }\end{array}$ \\
\hline
\end{tabular}

\begin{tabular}{|l|l|l|}
\hline Nome & Idade & \multicolumn{1}{c|}{ Memórias musicais } \\
\hline Roberta & 28 & $\begin{array}{l}\text { "Tinha, quando eu era pequena, e até hoje eu passei } \\
\text { pro meu filho, eu tinha um piano que tinha as } \\
\text { notinhas, né, aquele bem de brinquedo mesmo...mas } \\
\text { tu via que até hoje eu me lembro. Passando pra ele, } \\
\text { hoje eu me lembro daquele início do 'Parabéns'". }\end{array}$ \\
\hline
\end{tabular}

\begin{tabular}{|l|l|l|}
\hline Nome & Idade & \multicolumn{1}{c|}{ Memórias musicais } \\
\hline Sofia & 21 & $\begin{array}{l}\text { "E, de influência assim da escola, eu me recordo } \\
\text { muito pouco, de professora ter trabalhado música em } \\
\text { escola... e até hoje eu frequento o mesmo colégio } \\
\text { que estudava quando era adolescente. Hoje eles } \\
\text { colocam som pro pessoal, para as crianças } \\
\text { escutarem, mas na minha época nunca tinha". }\end{array}$ \\
\hline
\end{tabular}

\begin{tabular}{|l|l|l|}
\hline Nome & Idade & \multicolumn{1}{c|}{ Memórias musicais } \\
\hline Viviane & 21 & $\begin{array}{l}\text { "Me lembro que às vezes eu me emocionava, } \\
\text { cantando. E a minha irmã também, Ela é seis anos } \\
\text { mais nova que eu, então ela gostava também. A } \\
\text { gente pegava a letra e ficava cantando em casa. Me } \\
\text { lembro que ela começava a cantar e chorava. } \\
\text { Chorava assim de escorrer lágrimas". }\end{array}$ \\
\hline
\end{tabular}




\begin{tabular}{|l|l|l|}
\hline Nome & Idade & \multicolumn{1}{c|}{ Memórias musicais } \\
\hline Yasmin & 22 & $\begin{array}{l}\text { "Eu me lembro que na época o tal do 3 em 1, foi uma } \\
\text { coisa...Então meu pai deu um jeito e foi comprar o 3 } \\
\text { em 1 e de vez em quando engatava o dele no } \\
\text { amplificador para mostrar para a vizinhança que } \\
\text { estava feliz da vida". }\end{array}$ \\
\hline
\end{tabular}

\section{Narrativas finais}

Entre as memórias de Viviane com as letras das músicas entrelaçadas com as emoções e lágrimas, os com as narrativas de Margarete cantando as canções de ninar para suas filhas ou as lembranças de Gisele ouvindo e cantando ao som do Balão Mágico, fui chegando ao final destas narrativas, significados e histórias que foram sendo tecidos ao longo desse processo de recontar fragmentos de uma tese.

Assim, narrar é contar uma história para alguém, narrar-se é contar nossa história ou uma história da qual também somos, fomos ou nos sentimos personagens. As narrativas, então, oferecem em si a possibilidade de uma análise, se concebermos análise como um processo de produção de significados a partir de uma retroalimentação que se iniciaria quando o ouvinte/leitor/apreciador de um texto se apropria deste texto, de algum modo, tecendo significados que são seus, mesmo que produzidos de forma compartilhada, e constrói uma trama narrativa própria que será ouvida/lida/vista por um terceiro, retornando ao início do processo (CURY, 2013, p.155).

Trago esse excerto do trabalho de Cury (2013) para me auxiliar nas narrativas finais desse artigo, com o desejo de compartilhar com os leitores esses significados produzidos ao longo da tese através das narrativas das entrevistadas.

$\mathrm{Na}$ tentativa de juntar os fios desse tear (auto)biográfico, ressalto que após selecionar trechos das falas das entrevistadas na tese, com narrativas de suas memórias musicais impregnadas que subjetividades vividas, de cenas familiares, mescladas com aspectos geracionais visto que havia um grupo de entrevistadas na faixa dos 50 anos e uma grande maioria na faixa dos 20 anos, busquei fazer as finalizações desses movimentos e narrativas. Como havia trabalhado na perspectiva de desenvolver uma análise baseada nas múltiplas leituras do material, compondo um exercício constante de ir e vir, num ler e reler as narrativas orais e escritas, me propus a realizar essa etapa da tese e, desta maneira, poder organizar e descrever como se constituíram e estão sendo constituídas as identidades musicais dessas alunas.

Trago, portanto, nos limites deste texto, alguns trechos que selecionei das autobiografias musicais dessas entrevistadas, como uma apresentação de um grupo musical, com suas escolhas, gostos e lembranças de diferentes momentos da vida, entre movimentos de Biodança e aulas de música, ou entre os sons das músicas da juventude, as letras e os aparelhos de som para reprodução dos discos. Um universo musical eclético, com memórias musicais diversas e imbricadas com as 
narrativas de si desse grupo de mulheres que traziam do seu cotidiano musical sonoridades, timbres, ritmos, coreografias, hinos religiosos e melodias românticas.

Considero também importante retomar aqui algumas semelhanças e diferenças que percebi entre as narrativas orais, através das entrevistas, e as narrativas escritas, com as autobiografias, que foram significantes para proceder a análise desse material. O primeiro aspecto que destaco é em relação ao tamanho das narrativas, pois as escritas foram sempre bem mais curtas e sucintas do que as produzidas oralmente. Outra característica que observei refere-se aos textos das autobiografias, que em muitos exemplos desencadearam reflexões sobre questões relacionadas às memórias musicais das entrevistadas. Em algumas autobiografias havia a presença de discursos que analisavam as próprias narrativas de si.

Ao finalizar essas narrativas retorno ao campo da pesquisa biográfica e diálogo com as palavras de Formenti (2013) ao salientar que "as narrativas - orais, escritas, visuais ou performáticas - de sujeitos adultos são geradas e trocadas em específicos contextos e dispositivos relativos à pesquisa, para serem, então, analisadas, organizadas e transformadas em uma "teoria satisfatória". A autora complementa suas reflexões e ressalta que neste campo emergem proposições "que pretendem transmitir uma maior compreensão das experiências pesquisadas e dos fenômenos aos quais fazem referência" (2013, p.109).

Certamente as condições de produção dessas narrativas foram diferentes. Enquanto, na situação das entrevistas, as alunas eram questionadas diretamente e tinham uma interlocutora presente e atenta (a entrevistadora), na escrita da autobiografia, a interlocução se dava com a imagem da pesquisadora, sem a pressão da troca falada. Acresça-se a isso a maior exigência formal em relação à escrita, exigência essa de que, como universitárias, têm conhecimento.

No rol de lembranças que afloraram ao longo desse processo de movimentos de uma tese, vieram os questionamentos sobre o mundo vivido com as experiências como educadora musical e os desafios com as tentativas de articular relações entre os temas e problemas de pesquisa na perspectiva de buscar uma transcendência nos escritos da tese e as articulações com as práticas vividas. Foram vários ensaios e questionamentos no sentido de começar a compor estes escritos narrativos em um trabalho que revisitava uma pesquisa com narrativas de si, mas tentando manter o foco de ser um trabalho acadêmico, de mesclar e tecer as narrativas desse grupo de vinte mulheres com minhas narrativas de mulher, mãe, professora de música, amiga, irmã, avó, pesquisadora, dentre outras, ancoradas no espaço (auto)biográfico.

\section{REFERÊNCIAS}

ARFUCH, Leonor. O espaço biográfico: dilemas da subjetividade contemporânea. Rio de Janeiro: EDUERJ, 2010.

CHASSOT, Ático. Memórias de um professor - Hologramas desde um trem misto. Ijuí: Editora Unijuí, 2012. 
CURY, Eduardo Guedes. De Narrativas a Análises Narrativas: reflexões sobre a análise de depoimentos em pesquisas de história da educação (matemática). In: ALEXANDRIA Revista de Educação em Ciência e Tecnologia, v.6, n.1, p. 143-164, abril 2013.

DELORY-MOMBERGER, Christine. Formação e socialização: os ateliês biográficos de projeto. In: Educação e Pesquisa. vol.32, no.2 São Paulo May/Aug. 2006

FREITAS, Denise de; GALVÃO, Cecilia. O uso de narrativas autobiográficas no desenvolvimento profissional de professores. In: Ciências \& Cognição; vol 12: 219-233, 2007.

GARCEZ, Pedro. Transcrição como teoria: a identificação dos falantes como atividade analítica plena. In: LOPES, Luiz. P da M.; CABRAL, Liliana B. (Org.). Identidade: recortes multi e interdisciplinares. Campinas, SP: Mercado das Letras, 2002.

FORMENTI, Laura. Identidade, Relação e contexto: Uma releitura epistemológica dos métodos Biográficos. Revista da FAEEBA - Educação e Contemporaneidade, Salvador, v. 22, n. 40, p. 105-117, jul./dez. 2013.

JOSSO, Marie-Christine. Experiências de Vida e Formação Docente. São Paulo: Cortez Editora, 2004

MAFFIOLETTI, Leda de Albuquerque, ABRAHÃO, Maria Helena. Significações acerca de si mesmo por meio de narrativas sobre experiência musical. Currículo sem Fronteiras, v. 16, n. 1, p. 42-58, jan./abr. 2016.

PAIS, José Machado. Vida cotidiana: enigmas e revelações. Rio de Janeiro: Cortez, 2003.

SOUSA, Maria Goreti, CABRAL, Carmen Lúcia. A narrativa como opção metodológica de pesquisa e formação de professores. Revista Horizontes, v. 33, n. 2, p. 149-158, jul./dez. 2015.

SOUZA, Elizeu Clementino. (Auto)biografia, histórias de vida e práticas de formação. In: NASCIMENTO, A. D., HETKOWSKI, T. M., (Org.). Memória e formação de professores. Salvador: EDUFBA, 2007.

SOUZA, Elizeu Clementino. Diálogos cruzados sobre pesquisa (auto)biográfica: análise compreensivainterpretativa e política de sentido. Revista Educação. Santa Maria | v. 39 | n. 1 | p. $39-50$ | jan./abr. 2014.

Recebido em 18/06/2017 Aprovado em 20/08/2017 